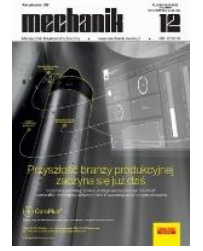

How to cite this article:

Authors: Łukasz Nowakowski, Wojciech Depczyński

Title of article: „Design and construction of a pressure stabilizing device of cement slurry used in Deep Soil Mixing Technology"

Mechanik, No. 12 (2018)

DOI: https://doi.org/10.17814/mechanik.2018.12.209

\title{
Design and construction of a pressure stabilizing device of cement slurry used in Deep Soil Mixing Technology
}

\author{
ŁUKASZ NOWAKOWSKI \\ WOJCIECH DEPCZYŃSKI *
}

\begin{abstract}
Dr inż. Łukasz Nowakowski, lukasn@tu.kielce.pl, , https://orcid.org/0000-0002-2425-7295 - Katedra Technologii Mechanicznej i Metrologii Politechniki Świętokrzyskiej, Kielce, Polska

Dr inż. Wojciech Depczyński, wdep@tu.kielce.pl, , https://orcid.org/0000-0001-5574-4937- Katedra Technologii Mechanicznej i Metrologii Politechniki Świętokrzyskiej, Kielce, Polska
\end{abstract}

The article describes research carried out for design and construction of devices stabilizing the working pressure of cement slurry, with use of Deep Soil Mixing (DSM).

KEYWORDS: Deep Soil Mixing Technology (DSM), pressure stabilizing device, cement slurry, bentonite

\section{Introduction}

The design and construction of a device stabilizing the working pressure of cement slurry, which was used in Deep Soil Mixing (DSM) technology, was described. This technology is used worldwide to reinforce a weak building foundation and consists in constructing columns (screens) of cement ground (fig. 1) [1]. A steel stirrer is introduced into the soil, which is usually turned clockwise. At the same time, leaven is applied to the loosened soil, the main components of which are water and cement.

This technique is more and more widely used and is the subject of intensive experimental research and theoretical works $[2,3]$.

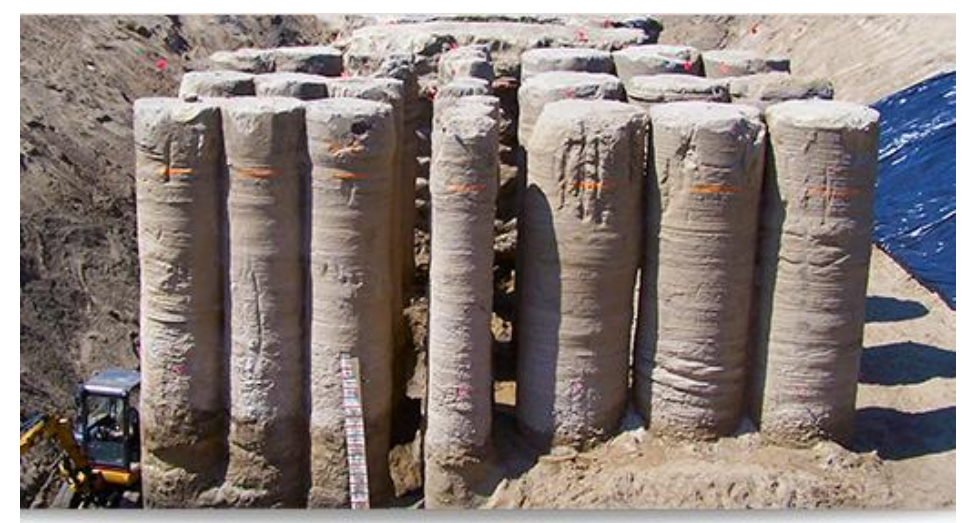

Fig. 1. Apertures made in DSM technology [1]

The AIE-400 electric injection aggregate from Bipromasz was used to supply the cement slurry. The aggregate (fig. 2) consists of two PPN-250 plunger mud pumps, working in pairs, in which the plungers work alternately to ensure continuity and uniformity of the pumped stream. The parameters of mud pumps are presented in tab. I [4].

One of the disadvantages of plunger pumps is the pulsation of the pumped medium, which, if the injection system is operated without a pressure stabilizing device (pulsation damper), leads to damage to the injection lines. 


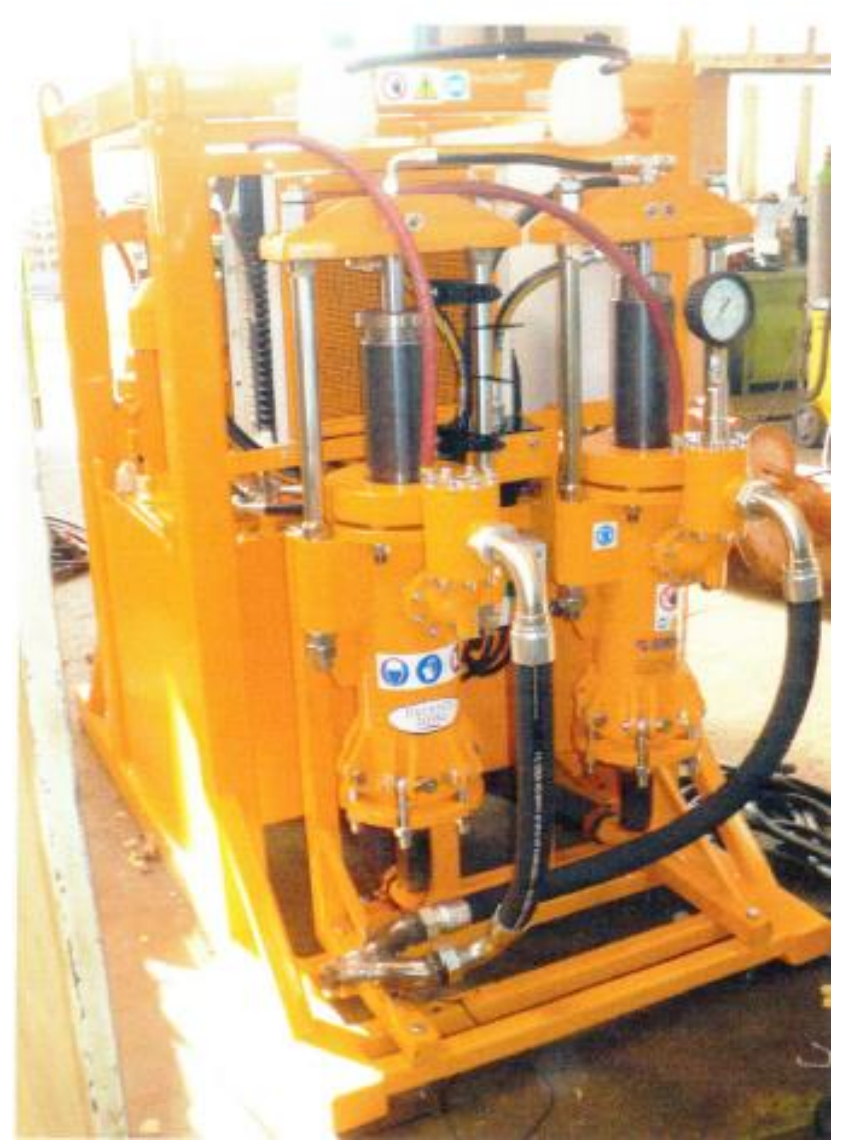

Fig. 2. AIE-400 injection aggregate [4]

TABLE I. Operating parameters of the AIE-400 injection aggregate

\begin{tabular}{|l|c|}
\hline Mud pump & PPN-250-2 pieces \\
\hline Inject & cement and bentonite suspensions \\
\hline Capacity per cycle & $4.6 \times 2 \mathrm{dm}^{3}$ \\
\hline Performance included in the assembly AIE-400 & to $400 \mathrm{dm}^{3} / \mathrm{min}$ \\
\hline Maximum pressure & $4(6$ for micropiles $) \mathrm{MPa}$ \\
\hline Drive & actuator $50 / 36 \times 250 \mathrm{AH}$ \\
\hline
\end{tabular}

Manufacturers of injection aggregates recommend the use of an additional silencer (compensator) on the discharge line, the main task of which is to significantly reduce pressure pulsations in the widest possible frequency band with slight pressure losses, regardless of temperature or pressure fluctuations. Unfortunately, commercially available design solutions of pulsation dampers are not adapted to work with cement and bentonite slurries, because they have limited self-cleaning ability during continuous operation, as a result of which a lot of dirt remains in the damper chamber, which leads to damage to the device.

This paper presents a design solution for a piston pulsation damper with a system of continuous cleaning of the cylinder internal surfaces during operation.

\section{Design of a pressure stabilizing device}

The aim of the project was to develop a piston pulsation damper with a system of continuous cleaning of internal surfaces of the cylinder during operation, designed to reduce the pressure pulsation of cement and bentonite suspensions.

The developed structure of the pressure stabilizing device has a body with holes supplying and discharging the working medium. The body has also a cylinder sealed with a rubber ring.

Cylinder head with a pressure gauge and a four-pipe supplying working gas (nitrogen) to the cylinder is installed on the cylinder. A piston is mounted in the cylinder, which divides the cylinder chamber into an upper 
part - above the piston - and a lower part - under the piston. A spring is attached to the piston and upper body, the side edges of which are resting on the inner surface of the cylinder.

In the lower part of the body, a truncated cone is installed, in which a tube with a liquid distribution nozzle attached inside the lower chamber is mounted.

In the developed solution, the nozzle has the shape of a truncated cone with holes arranged radially on the forming cone and an opening located axially on the face of the nozzle.

The piston is equipped with a socket, the shape of which corresponds to the shape of the nozzle.

\section{Principle of pressure stabilizing device work}

The fluid medium pumped by a piston or plunger pump, including non-Newtonian fluid or suspension, is fed to the pulsation damper via a conduit connected to the inlet of the fitting 14 embedded in the sleeve 13 . Then the liquid flows through the pipe 15 and the nozzle 16, thereby filling the lower chamber 11 under the piston 9. The task of the nozzle 16 is to mix, form and direct the liquid stream so that it rinses the inner walls of the cylinder 4 and puts the elastic element 12 into additional vibrations that will intensify the process of mechanical cleaning of the inner surfaces of the cylinder 4.
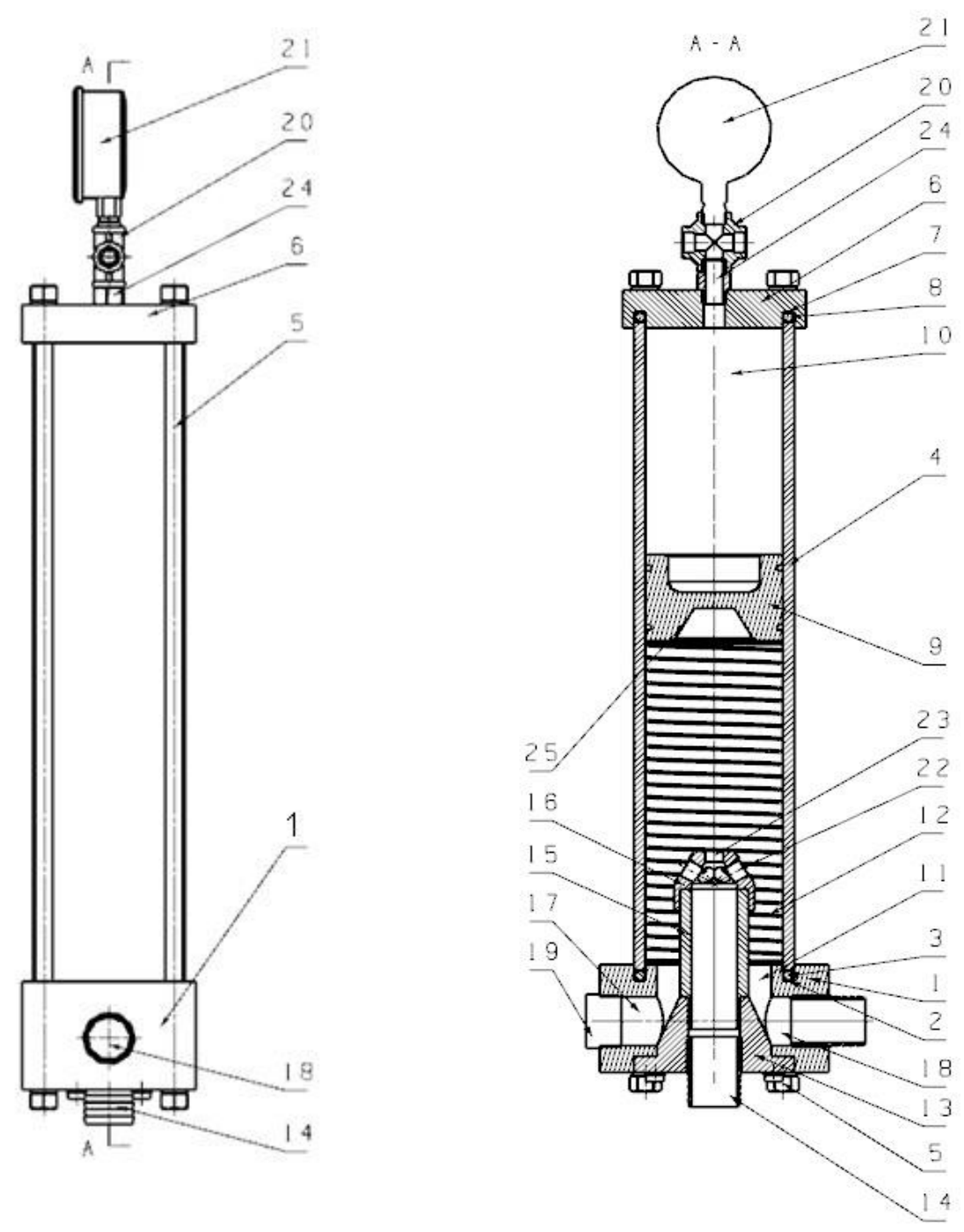

Fig. 3. Pressure stabilizing device [8]: 1 - body, 2 - annular groove, 3 - rubber ring, 4 - cylinder, 5 - connecting screws, 6 - head, 7 - annular groove, 8 - 0-ring, 9 - piston , 10 - upper chamber above the piston, 11 - lower chamber below the piston, 12 - spring element, 13 - conical sleeve, 14, 18 - inlet, 15 - pipe, 16 - nozzle, 17 - inspection hole, 19 - plug, 20 - intersection, 21 - pressure gauge, 22, 23 - nozzle holes, 24 connector, 25 - socket 
Continuous pressure change caused by the pump action affects the piston 9, which moves axially up and down along the cylinder 4 . The change in piston position 9, caused by the change in the volume of the lower chamber 11 relative to the upper chamber 10 , allows the pulsation of the pumped liquid to be suppressed by compressing and the expansion of the gas in the upper chamber 10 above the piston 9. The upward and downward moving piston 9 sets in motion a spring element 12, the edges of which rub against the inner surface of the cylinder 4 , causing its mechanical cleaning. The spring element 12 is made of a spirally wound elastic material, the cross section of which may have the outline of a circle, square, rectangle, triangle, trapezoid and their derivatives with concave or convex sides.

\section{Calculations of the pressure stabilizing device}

The first stage of calculations of the pressure stabilizing device was to determine the volume of the working gas, on the basis of which the overall dimensions of the piston and cylinder height were determined. In order to determine the minimum required volume of working gas, the applications of producers of commercially available devices suppressing pulsations of the working medium [5, 6] and work [7], comprehensively describing the phenomena were used.

TABLE II. Parameters for determining the volume of working gas in the chamber of the pressure stabilizing device

\begin{tabular}{|l|c|}
\hline Temperature & $20^{\circ} \mathrm{C}$ \\
\hline Pump capacity & $400 \mathrm{~L} / \mathrm{min}$ \\
\hline Pump type & Single Acting \\
\hline Number of pump cycles & $53 / \mathrm{min}$ \\
\hline Number of cylinders & 2 spieces \\
\hline Pumping pressure & $40 \mathrm{bar}$ \\
\hline Residual pulsation & $8.1 \%$ \\
\hline
\end{tabular}

TABLE III. Input data and calculation procedure for the dimensions of the pressure stabilizing device

\begin{tabular}{|c|c|}
\hline \multicolumn{2}{|c|}{ Input data } \\
\hline Working pressure & $P_{\mathrm{p}}=40 \mathrm{bar}$ \\
\hline Piston diameter & $d_{\mathrm{t}}=120 \mathrm{~mm}$ \\
\hline Minimal gas density & $v_{\mathrm{k}}=15 \mathrm{~L}$ \\
\hline \multicolumn{2}{|c|}{ Calculations } \\
\hline \multicolumn{2}{|c|}{ Piston surface area } \\
\hline$A_{k}=\pi \cdot\left(\frac{d_{t}}{2}\right)^{2}$ & $A_{\mathrm{k}}=11309.7 \mathrm{~mm}^{2}$ \\
\hline \multicolumn{2}{|c|}{ Cylinder height } \\
\hline$h_{k}=\frac{v_{k}}{\pi \cdot\left(\frac{d_{t}}{2}\right)^{2}}$ & $h_{\mathrm{k}}=1326.3 \mathrm{~mm}$ \\
\hline \multicolumn{2}{|c|}{ Force on the piston } \\
\hline$F_{k}=p_{p} \cdot A_{k}$ & $F_{\mathrm{k}}=45.2 \mathrm{kN}$ \\
\hline Corrosion allowance & Strength factor \\
\hline$c=2 \mathrm{~mm}$ & $k_{\mathrm{r}}=14 \mathrm{MPa}, z=1 \mathrm{~mm}$ \\
\hline \multicolumn{2}{|c|}{ Cylinder wall thickness } \\
\hline$g=\frac{p_{p} \cdot d_{t}}{\left(2.3 \cdot k_{r}-p_{p}\right) \cdot z}+c$ & $g=3.24 \mathrm{~mm}$ \\
\hline \multicolumn{2}{|c|}{ Bottom thickness } \\
\hline$h_{d}=0.433 \cdot d_{t} \cdot \sqrt{\frac{p_{p}}{k_{r}}}$ & $h_{\mathrm{d}}=8 \mathrm{~mm}$ \\
\hline
\end{tabular}

Data used to determine the volume of working gas in the chamber of the pressure stabilizing device is presented in tab. II. 
The following calculation results were obtained: minimum working gas volume $\sim 10 \div 15 \mathrm{l}$, initial loading pressure 24 bar.

Knowing the volume of working gas, a piston diameter of $\varnothing 120 \mathrm{~mm}$ was chosen, on the basis of which the cylinder height of the pressure stabilizing device was determined. The input data and the calculation procedure of other overall dimensions of the pressure stabilizing device are presented in tab. III.

\section{Selection of materials from which the pressure stabilizing device will be made}

After calculating the minimum working gas volume and overall dimensions of the device for stabilizing the working pressure, the type of material and overall dimensions of the semi-finished products, from which the device will be built, were selected. They are listed in tab. IV.

TABLE IV. Material type and overall dimensions of blanks

\begin{tabular}{|c|c|c|}
\hline Part & Material & Dimensions, mm \\
\hline Head & C45 & $160 \times 160 \times 35$ \\
\hline Body & C45 & $200 \times 160 \times 100$ \\
\hline Cylinder & St52.3 & $\emptyset 120 \mathrm{H} 8 \times 1400$ \\
\hline Conical sleeve & C45 & $\emptyset 150 \times 80$ \\
\hline Piston & C45 & $\emptyset 130 \times 85$ \\
\hline Pipe & C45 & $\emptyset 60 \times 500$ \\
\hline Nozzle & C45 & $\emptyset 150 \times 80$ \\
\hline
\end{tabular}

\section{Machining the elements of the pressure stabilizing device}

Fig. 4 presents selected components of the pressure stabilizing device.

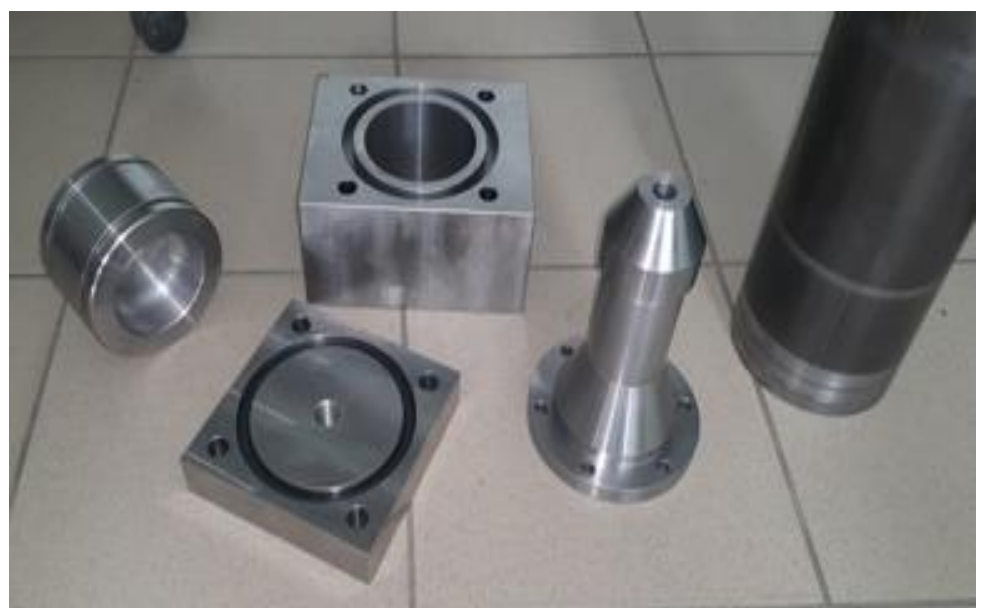

Fig. 4. Parts of the pressure stabilizing device

\section{Summary}

The design and assembly works carried out, aimed at developing and building a device for stabilizing the working pressure of cement slurry, which is used in DSM technology, indicate that the construction assumptions have been met.

Fig. 5 compares the 3D model with a built-in pressure stabilizing device.

We have managed to develop a device that has the ability to self-clean during continuous operation. Preliminary tests have shown that the nozzle with the holes arranged radially on the forming cone directs the liquid stream as intended, causing the cylinder walls to be rinsed and cleaned. The solution became the subject of a patent application entitled "Pressure pulsation damper" [8]. 

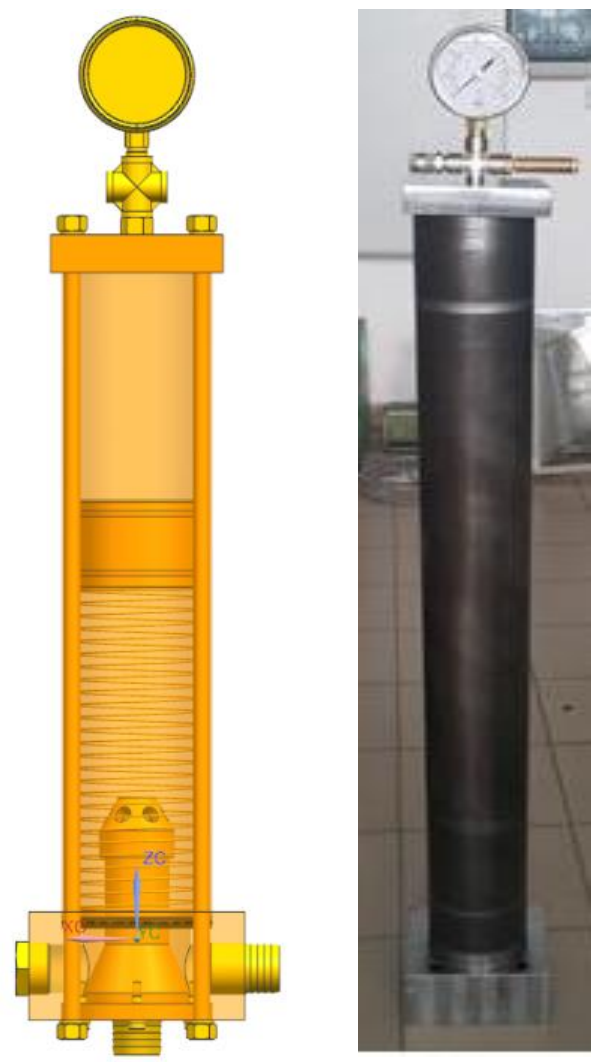

Fig. 5. View of the 3D model and the finished device for pressure stabilization

Construction of the pressure stabilizing device was carried out as part of the project "Modern and innovative land injection technologies", co-financed from European funds. The project is implemented by Ekokanwod Czyszczoń i Półtorak sp.j.

\section{REFERENCES}

[1] http://www.toutpourleforage.com/deep-soil-mixing-definition-usages/.

[2] Zaika Y., Rachmansyah A. „The estimation of bearing capacity and swell potential of deep soil mixing on expansive soil by small scale model test". International Journal of GEOMATEl.13, 38 (2017): s. 09-15. Geotec., Const. Mat. \& Env., ISSN:2186-2990, Japan, DOI:http://dx.doi.org/10.21660/2017.38.6527.

[3] Pittaro G.A. "Use of pressure relief wells to optimize ground improvement layer thickness in deep excavations". Geotechnical Engineering. 48, 2 (2017): s. 80-85.

[4] Manual „Agregat iniekcyjny elektryczny AIE-400” 2017.

[5]https://www.hydac.com/pl-pl/serwis/download/oprogramowanie/software-download/speichertechnik.html.

[6] https://www.hk-hydraulik.com/pl/kalkulator-hydrauliczny.

[7] Kudźma Z. „Tłumienie pulsacji ciśnienia i hałasu w układach hydraulicznych $w$ stanach przejściowych i ustalonych". Wrocław: Oficyna Wydawnicza Politechniki Wrocławskiej, 2012.

[8] Nowakowski Ł., Depczyński W. „Tłumik pulsacji ciśnienia”. Zgłoszenie patentowe P.424788, 2018

Fundusze

Europejskie

Program Regionalny
Rzeczpospolita Polska
WOJEWÓDZTWO ŚWIĘTOKRZYSKIE
Unia Europejska

Europejski Fundusz Rozwoju Regionalnego

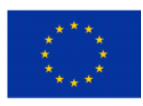

